Review Article

\title{
Effect of Acupuncture on Chronic Pain with Depression: A Systematic Review
}

\author{
Bin Yan, ${ }^{1}$ Shibai Zhu, ${ }^{2}$ Yu Wang, ${ }^{3}$ Gula Da, ${ }^{4}$ and Guoqing Tian ${ }^{1}{ }^{1}$ \\ ${ }^{1}$ Department of Traditional Chinese Medicine, Peking Union Medical College Hospital, Chinese Academy of Medical Sciences, \\ Beijing, China \\ ${ }^{2}$ Department of Orthopedic, Peking Union Medical College Hospital, Chinese Academy of Medical Sciences, Beijing, China \\ ${ }^{3}$ Department of Nursing, Peking Union Medical College Hospital, Chinese Academy of Medical Sciences, Beijing, China \\ ${ }^{4}$ Department of Rheumatology and Immunology, Peking Union Medical College Hospital, Chinese Academy of Medical Sciences, \\ Beijing, China \\ Correspondence should be addressed to Guoqing Tian; gq-tian@163.com
}

Received 24 April 2020; Accepted 10 June 2020; Published 25 June 2020

Guest Editor: Fengbiao Mao

Copyright ( 2020 Bin Yan et al. This is an open access article distributed under the Creative Commons Attribution License, which permits unrestricted use, distribution, and reproduction in any medium, provided the original work is properly cited.

Background. Numerous studies suggested that chronic pain and depression were closely related and widespread in the population. When patients have symptoms of chronic pain and depression, the corresponding treatment will become difficult. Acupuncture, a unique therapeutic method of traditional Chinese medicine, has been reported to potentially serve as an alternative treatment for patients with comorbid chronic pain and depression by many research studies. Methods. A comprehensive search was conducted through the online database, including the Cochrane Library, PubMed, EMBASE, SinoMed, CNKI, and Wanfang database. Trials were RCTs published in the English or Chinese language, recruiting participants with chronic pain and depression comorbidity. The primary outcomes were the Visual Analogue Scale (VAS) and Hamilton Depression Scale (HAMD). Statistical analyses were conducted using Review Manager 5.3. Each trail was quality appraised with the five-point Jadad Score. Results. 7 eligible RCTs involving 535 patients were included. Better therapeutic effect and safety could be observed in the experimental group compared with the control group. There was a significant decrease in the VAS (mean difference $(\mathrm{MD})=-0.68(-1.24,-0.12), P=0.02)$ and HAMD (MD $=-2.18(-3.09,-1.26), P<0.00001)$ scores and the incidence of adverse events between two groups. Conclusion. In the treatment of chronic pain with depression, acupuncture could not only get better clinical efficacy, but also have higher security compared with medicine therapy, which can be used in patients with poorer response to the conventional medication or suffering from serious side effects.

\section{Introduction}

According to the definition of chronic or persistent pain given by the International Association for the Study of Pain, if the pain lasts longer than 3 months or beyond the time period when an acute insult would have been expected to heal, it becomes a chronic condition [1]. Chronic pain is considered one of the most prevalent physical conditions in developed countries, affecting approximately 1 in 10 adults [2]. Since pain is "an unpleasant sensory and emotional experience associated with actual or potential tissue damage, or described in terms of such damage," depression and pain always co-occur [3]. Additionally, the physiological and emotional burden of chronic pain and a lack of efficient treatments might act as barriers to recovery and contribute to the development of persistent pain and major depression [4].

Depression is prevalent around the world, affecting more than 350 million people worldwide [5]. A recent up-to-date article noted that depression is the most common psychiatric disorder in the general population and the most common mental health condition in patients seen in primary care [6]. It is also a leading cause of disability and can cause high levels of distress and increased risk of suicide [7]. The World Health Organization (WHO) projected that depression will rank the largest burden of disease worldwide by 2030 [8]. In 
practice, for the diagnosis of depression, the two main classificatory diagnostic systems, the Diagnostic and Statistical Manual of Mental Disorders and the International Classification of Diseases, rely on the identification of some key symptoms [9]. Therefore, depression is a disorder with symptoms forming a syndrome and causing functional impairment, which can lead to considerable loss of productivity and quality of life.

As two of the most widespread disorders, studies suggested that pain and depression were closely related [10]. The combination of these two disorders can exacerbate the experience of one's health state, interfere with people normal functioning, and decrease the quality of life seriously [11]. A substantial proportion (30\% to $45 \%$ ) of patients with chronic pain present with frank symptoms of depression [12], and also $52 \%$ to $65 \%$ of patients with depression suffer from chronic pain [13]. Mental distress contributes to more serious pain, at the same time to greater pain-related disability and poorer response to the pharmacological treatment $[5,14]$. In other words, chronic pain and depression create a vicious cycle in which pain worsens symptoms of depression, and then the resulting depression worsens feelings of pain. Studies have shown that depression and chronic pain share some of the same neurotransmitters and nerve pathways [15]. However, the causal association between depression and chronic pain is yet unclear.

In view of the biopsychosocial aspects involved in chronic pain, a multimodal approach to management is essential [16]. This usually involves pharmacological or nonpharmacological therapy or both. Many guidelines $[17,18]$ recommended acetaminophen as the first-line agent for chronic pain due to its safety and tolerance. However, it is not an ideal choice for chronic inflammatory pain (such as rheumatoid arthritis and osteoarthritis) compared with nonsteroidal anti-inflammatory drugs (NSAIDs) due to the lack of anti-inflammatory activity [19]. COX2-selective and nonselective NSAIDs are particularly helpful in treating an inflammatory type of pain, which display both analgesic and anti-inflammatory properties [20]. However, the side effects also need to be vigilant, especially the gastrointestinal and cardiovascular events [21, 22]. Generally, from a pharmacological perspective, opioids are considered as the most powerful painkillers [23]. In addition, these medications have been increasingly used for the treatment of chronic nonmalignant pain which failed response to other medications [24]. However, previous reports also have indicated the prescription opioid misuse $[2,25]$ and death [26] in the comorbidities of the joint drug problem. Other medications, including anticonvulsants, serotonin-norepinephrine reuptake inhibitors (SNRIs), antidepressants, benzodiazepines, muscle relaxants, and topical lidocaine, all have their own indications and adverse reactions [27]. Thus, the points on the management of chronic pain have shifted to a multimodal and multidisciplinary therapy, and it also includes psychological (mindfulness meditation and cognitive behavioral therapy), rehabilitative, interventional, and complementary/alternative therapies [27-30].

Conventional treatment of depression mainly includes medication, psychotherapy, and physiotherapy. Taking antidepressants as the most preferred treatment of this disease, only a third of patients with depression respond fully to antidepressant medication [31]. Long-term side effects and drug dependence make patients less compliant with them. Although evidence-based studies confirmed that cognitive behavioral therapy (CBT) was effective [32], its effect was a gradual and cumulative process, which was slower than that of drugs. Therefore, patients are often more willing to accept drug treatment than to tolerate the gradual process in the early stage. Physical therapy includes electroconvulsive therapy (ECT), vagal nerve stimulation (VNS), and transcranial magnetic stimulation (TMS). Although the safety and efficacy of physical therapy have been verified by some studies [33-35], the effectiveness varies from person to person [36]. Therefore, for some special types of depression, such as chronic, refractory, severe, and adolescent, the combined treatment model has become a new trend of depression treatment $[31,34]$. In brief, medication, psychotherapy, and physiotherapy have been shown to be effective, but the actual clinical effect is unsatisfactory.

In terms of management for chronic pain and depression comorbidity, there was a significant overlap in the pharmacological treatment $[28,37]$. However, these medicine cotreatments may induce new clinical issues due to drug-todrug interactions or drug-related adverse events. For instance, application of opioids can relieve chronic pain effectively, but it was agreed that it can also cause severe dependence and addiction in patients [38], and long-term use of opioids has been confirmed to increase the risk of depression [39]. Benzodiazepines, a kind of antidepressants, do not have analgesic effect; however, up to one-third of patients taking opioids for chronic pain have reported taking benzodiazepines simultaneously, which may increase the risk of sedation and respiratory depression [40]. Therefore, it is necessary to find another treatment method with good therapeutic effect and little side effects.

Acupuncture, a unique therapeutic method of traditional Chinese medicine with a history of thousands of years, has become a widely recognized alternative and complementary therapy in clinical practice [41]. Acupuncture uses needles to stimulate specified acupuncture points, which has the advantages of simple operation, economical cost and few side effects, and it has obvious curative effect on pain and depression separately. Many clinical research studies have verified that acupuncture is an effective treatment for patients with cancer pain, migraine, and low back pain [42-44]. There are also many randomized controlled trials having confirmed that acupuncture can alleviate depression and improve patients' quality of life $[45,46]$. As the optimized comorbid chronic pain and depression management is to allow progress in restoring function while reducing longterm reliance on medical therapy [47], acupuncture may potentially serve as an alternative treatment for patients with comorbid chronic pain and depression.

To date, there have been several systematic reviews of acupuncture in the treatment for chronic pain or for depression [48, 49]. However, the effect of acupuncture as a treatment for chronic pain and depression comorbidity is questionable, and there is no systematic review of the use of 
acupuncture for comorbid chronic pain and depression, so the experts may confront problems to conduct further research in the related field. Therefore, a comprehensive systematic review of acupuncture in the treatment for chronic pain with depression is needed.

\section{Methods}

2.1. Search Strategy. A comprehensive search for studies about the effectiveness of acupuncture for chronic pain with depression was conducted through the online database. The following electronic databases were searched from inception to March 17, 2020: the Cochrane Central Register of Controlled Trials, PubMed, EMBASE, Chinese Biomedical Database (SinoMed), China National Knowledge Infrastructure (CNKI), and Wanfang database. The following terms were used: "chronic pain" OR "pain, chronic" AND "depression" OR "depressive disease" OR "depressive disorder" AND "acupuncture therapy" AND "random." During searching Chinese databases, the similar search strategy with Chinese terms was adopted. The initial database search was done by 3 authors (Yan, Zhu, and Wang) independently to ensure reproducibility.

\subsection{Inclusion and Exclusion Criteria}

2.2.1. Type of Study. Trials were eligible if they were randomized controlled trials (RCTs) recruiting participants with chronic pain and depression comorbidity, regardless of whether there was single blind, double blind, or nonblind.

2.2.2. Type of Participant. Patients diagnosed with chronic pain combined with depression or depression combined with chronic pain will be included. The main concern of studies cited must be chronic pain and depression, that is to say, the author must explain the definition or diagnostic criteria for chronic pain and depression. There will be no limits on the age, sex, and source of cases.

2.2.3. Intervention. Patients in the experimental group were treated with acupuncture alone or in combination with other therapy, while those in the control group were subjected to other therapy without acupuncture for chronic pain with depression.

2.2.4. Outcome Measures. The primary outcomes of interest were the pain scores and depression severity, i.e., Visual Analog Scale (VAS): higher scores indicate more severe pain, and Hamilton Depression Scale (HAMD): higher scores indicate a greater degree of depression, and to observe the changes of indicators before and after intervention. The secondary outcomes included any adverse events, i.e., Treatment Emergent Symptom Scale (TESS) or Rating Scale for Side Effects (SERS).

2.2.5. Exclusion Criteria. In order to evaluate the independent effects of acupuncture, the following trials were excluded: (1) conference abstracts, review articles, animal studies, cadaveric studies, in vitro studies, or articles published in a form other than clinical trials; (2) any control group that included acupuncture therapies; (3) literatures without relevant indicators or quantitative data; (4) evaluation indicators include only chronic pain or only depression; (5) repeated published literature.

2.3. Selection of Studies. 4 authors (Yan, Zhu, Wang, and Da) independently screened all potential eligible studies. Titles and abstracts were first screened to exclude irrelevant papers. Full text of all articles of potentially relevant abstracts were retrieved and screened according to the study inclusion and exclusion criteria. Final article selection was done independently by all four reviewers, and disagreements were resolved by consensus.

2.4. Quality Assessment. 4 authors (Yan, Zhu, Wang, and $\mathrm{Da}$ ) independently conducted the methodological quality of all included studies. Each article was quality appraised with the five-point Jadad Score [50]. Three factors associated with risk of bias were evaluated: randomization, blinding, and follow-up. The specific scoring criteria are as follows: when the study provides a detailed description of randomization, such as using a random number table, 2 points are obtained; if only a random method is used and there is no exact description, 1 point is obtained; if there is no random allocation, no score. 2 points were scored when the study used the appropriate placebo or a similar method; 1 point was scored when the trial involved blinding and no description; no blinding means no score. When describing the follow-up and the reasons for loss of follow-up, score 1 point, otherwise no score. If the total score is greater than or equal to three, the paper is considered to be of high quality.

2.5. Data Extraction. Data were extracted into a prespecified data extraction table, with items including the authors' names, the year of publication, total sample size, age, gender, detailed intervention information of two groups, outcome measures, and adverse reactions.

2.6. Statistical Methods. Review Manager 5.3, provided freely by the Cochrane cooperation net, was applied for statistical analysis. The primary outcomes, VAS and HAMD, were both continuous variables, and mean difference (MD) was used as effect values. The confidence internal was set as $\alpha=0.05$.

\section{Results}

3.1. Results of the Search. A total of 521 references were retrieved after removing duplicates (Figure 1). 3 authors (Yan, Zhu, and Wang) independently screened these references. Based on the review of the title and abstract, 89 full-text papers were reviewed and 7 eligible RCTs [51-57] involving 535 patients were included. All 7 RCTs were conducted in China and were published between 2000 
and 2018. There were a total of 265 participants receiving acupuncture alone or in combination with other therapy (experimental group) and 270 receiving other therapy without acupuncture (control group). Table 1 shows the distributions of sex, age, and time since diagnosis between the experimental and control groups, and the detailed intervention information is shown in Tables 2 and 3.

3.2. Comparison of the Pain-Related Score. A total of 6 studies assessed pain [51-56], and 5 of them used the VAS score $[51,53-56]$, while the other one used the comprehensive headache score [52]. The evaluation time point of each study was different, and most studies chose pretreatment and 4 weeks after treatment as time points for pain assessment (Table 4). There was no significant difference in VAS between the two groups before therapy. After 4 weeks of treatment, VAS decreased significantly in both groups, and the experimental group was more significant than the control group $(\mathrm{MD}=-0.68 \quad(-1.24,-0.12), \quad P=0.02$, $I^{2}=85 \%$ ) (Figure 2). However, there was a high degree of heterogeneity in the study $\left(I^{2}=85 \%\right)$. Sensitivity analysis reduced heterogeneity $\left(I^{2}=20 \%\right)$ (Figure 3 ) after deleting a study whose data were apparently different from the others.

3.3. Comparison of the Depression-Related Score. In the eligible RCTs, all trials conducted the depression-related assessments, and HAMD was used in 6 of them [51, 53-57]. Similar to the VAS, most studies included the time point of pretreatment and 4 weeks after treatment (Table 5). There was no significant difference in HAMD between the two groups before therapy. After 4 weeks of treatment, HAMD decreased significantly in both groups, especially in the experimental group, which indicates that there was a significant difference between the two groups $(\mathrm{MD}=-2.18$ $\left.(-3.09,-1.26), P<0.00001, I^{2}=52 \%\right)$ (Figure 4). Similarly, because of the high heterogeneity, after removing a research, the heterogeneity was significantly declined (Figure 5).

3.4. Security Assessment. All studies recorded adverse events during treatment in both groups. Incidence of adverse events was recorded in 5 studies [51-54,56], and other security assessments included TESS $[53,57]$ and SERS [55]. 2 studies reported no difference in the incidence of adverse events between the two groups $[53,54]$, and other studies have shown that acupuncture therapy could significantly reduce the incidence of adverse events and the adverse event-related score (Table 6).

3.5. Quality Assessment. The quality assessment of the trials was performed using the five-point Jadad Score (Table 7). Randomization was mentioned in all included studies, but only one had a detailed description of it [51]. Blind method cannot be used in research due to the characteristic of acupuncture. Besides, only two trails describe the details of follow-up [51, 52].

\section{Discussion}

This study is a comprehensive systematic review of acupuncture in the treatment for chronic pain with depression. There were significant differences in the VAS score and HAMD, decreasing between the two groups after treatment, indicating that acupuncture used alone or in combination with medication therapy can relieve pain and depression better than medication. Patients in the experimental group had lower incidence of adverse events and side effect scores, which proved the safety of acupuncture. The above results suggested that acupuncture has not only a better clinical result on the treatment of chronic pain with depression but also has a higher security compared with medication therapy.

When it comes to acupuncture therapy, we found that different individual studies might utilize different acupoints, but from these prescriptions we could also find something in common. In practice, there are many ways to select acupoints during acupuncture treatment. Selection of local acupoints around the pain location was the main method to treat pain. In the treatment of depression, acupoints on the head were selected more frequently, such as Governor Vessel (GV) 20, GV 24, Extra-points of Head and Neck (EX-HN) 1, and EX-HN 3. In addition, some distal acupoints were also be selected, including Pericardium meridian of hand-jueyin (PC) 6, Heart meridian of hand-shaoyin (HT) 7, Spleen meridian of foot-taiyin (SP) 6, and Liver meridian of footqueyin (LR) 3. According to traditional Chinese medicine theory, human emotional activities are closely related to the five internal organs, so this explains why acupoints on multiple meridians can be selected for the treatment of depression.

The treatment of chronic pain and depression comorbidity has always been a tough problem because of poorer response to the pharmacological treatment and long-term side effects of drugs. Acupuncture, as an effective, simple, and economical treatment, has been used in the treatment of many diseases in China. The results of the systematic review suggested that acupuncture has a promising application prospect due to its unique advantages for the treatment of chronic pain with depression, and it can be used in patients with poorer response to the medication or suffering from serious side effects.

Previous systematic reviews of acupuncture for chronic pain and depression comorbidity are not available. However, findings from other chronic pain reviews and depressive disorder reviews are consistent with this review and indicate that acupuncture used alone or in combination with other treatment measures has a better therapeutic effect to the control group [49, 58-61].

There are many patients suffering from chronic pain with depression at present, and the findings of this systematic review provided a valuable alternative to these patients. However, most of the included articles had a quality score of no more than 2 points [52-57], and only 1 article got 3 points [51], which meant that the quality of the majorities was low. Considering the characteristics of acupuncture therapy itself, it is difficult to implement the blind method. 


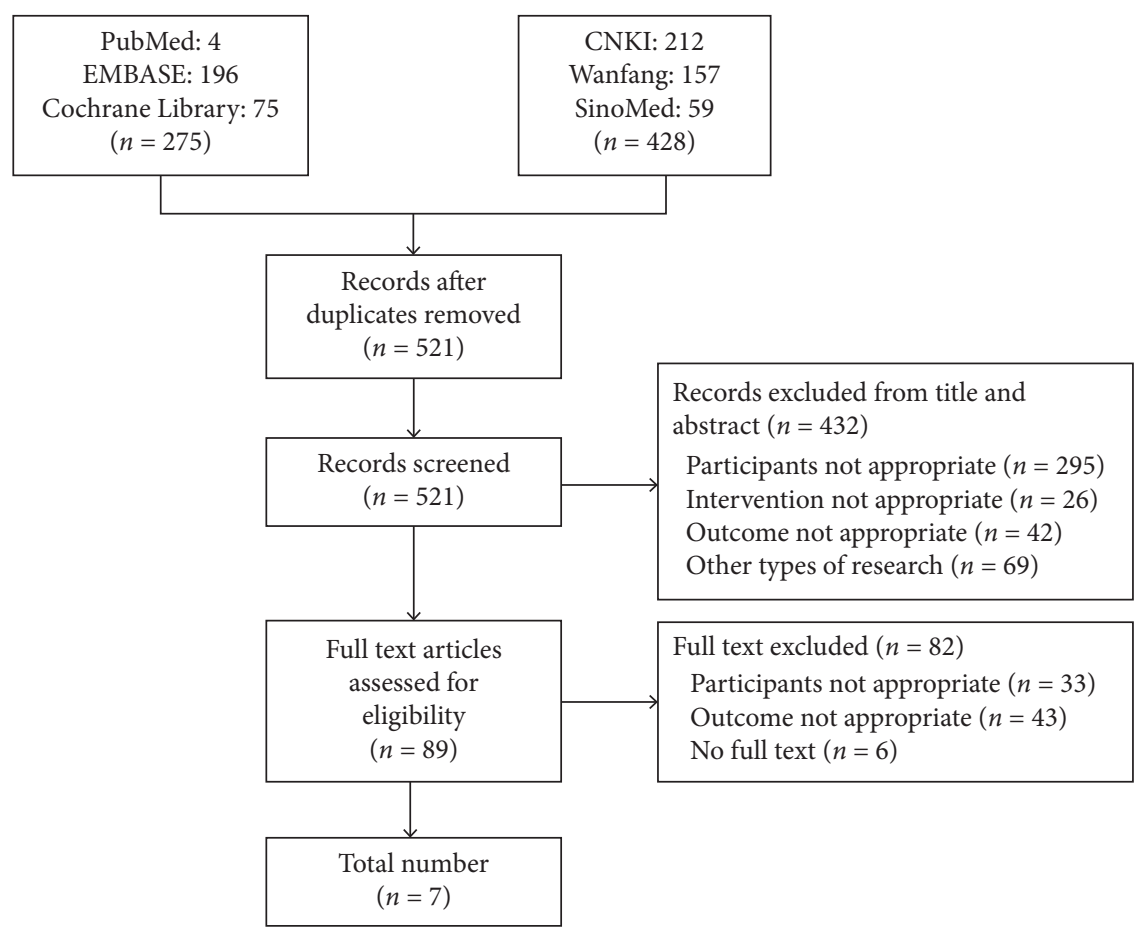

Figure 1: Study flow diagram.

TABLE 1: Basic information of 7 RCT studies.

\begin{tabular}{lccccccr}
\hline No. & \multirow{2}{*}{ Author } & \multirow{2}{*}{ Year } & Sample (EG/CG) & \multicolumn{2}{c}{ Age $(\mathrm{SD})$} & Gender (EG/CG) & Time since diagnosis (SD) (EG/CG) \\
\hline 1. [51] & Wang & 2012 & $60(30 / 30)$ & $51.5(4.1)$ & $50.3(4.7)$ & - \\
2. [52] & Xiao & 2015 & $48(24 / 24)$ & $53.17(9.89)$ & $50.58(8.80)$ & $8 / 16(\mathrm{M} / \mathrm{F}) / 10 / 14(\mathrm{M} / \mathrm{F})$ & - \\
3. [53] & Ma & 2015 & $128(64 / 64)$ & $39.93(12.93)$ & $38.69(14.19)$ & $27 / 37(\mathrm{M} / \mathrm{F}) / 29 / 35(\mathrm{M} / \mathrm{F})$ & $20.33(12.76) \mathrm{m} / 20.00(12.12) \mathrm{m}$ \\
4. [54] & Luo & 2018 & $84(42 / 42)$ & $57.15(11.26)$ & $57.39(11.58)$ & $22 / 20(\mathrm{M} / \mathrm{F}) / 23 / 19(\mathrm{M} / \mathrm{F})$ & $42.31(8.75) \mathrm{m} / 41.92(8.32) \mathrm{m}$ \\
5. [55] & Liu & 2013 & $90(45 / 45)$ & $47(8)$ & $48(8)$ & $15 / 30(\mathrm{M} / \mathrm{F}) / 16 / 29(\mathrm{M} / \mathrm{F})$ & $3.5(1.8) \mathrm{m} / 3.2(1.7) \mathrm{m}$ \\
6. [56] & Cao & 2008 & $60(30 / 30)$ & \multicolumn{2}{c}{$20-70$} & $23 / 37(\mathrm{M} / \mathrm{F})$ & $0.5-30 \mathrm{y}$ \\
7. [57] & Huang & 2000 & $65(30 / 35)$ & \multicolumn{2}{c}{$30.39(7.01)$} & $25 / 40(\mathrm{M} / \mathrm{F})$ & - \\
\hline
\end{tabular}

EG, experimental group; CG, control group; -, not available; $m$, month; $y$, year.

TABLE 2: Detailed intervention information 1.

\begin{tabular}{|c|c|c|c|c|c|}
\hline No. & $\begin{array}{l}\text { Study } \\
\text { type }\end{array}$ & Diagnosis & EG & CG & $\begin{array}{l}\text { Duration } \\
\text { (wks) }\end{array}$ \\
\hline 1 & RCT & Depression with chronic pain & Abdominal acupuncture & Deanxit & 4 \\
\hline 2 & $\mathrm{RCT}$ & Migraine with depression & Acupuncture & $\begin{array}{l}\text { Deanxit combined rizatriptan } \\
\text { benzoate tablets }\end{array}$ & 4 \\
\hline 3 & RCT & Depression with chronic pain & $\begin{array}{c}\text { Acupuncture combined } \\
\text { duloxetine }\end{array}$ & Duloxetine & 8 \\
\hline 4 & RCT & $\begin{array}{l}\text { Recurrent chronic trigeminal neuralgia } \\
\text { accompanied by depression }\end{array}$ & $\begin{array}{l}\text { Acupuncture combined } \\
\text { traditional Chinese medicine }\end{array}$ & Traditional Chinese medicine & 4 \\
\hline 5 & RCT & Depression with chronic pain & $\begin{array}{l}\text { Acupuncture combined SSRI } \\
\text { antidepressants }\end{array}$ & SSRI antidepressants & 4 \\
\hline 6 & RCT & Chronic pain with depression & Acupuncture & Deanxit & 4 \\
\hline 7 & RCT & Depression with chronic pain & Acupuncture & Amitriptyline & 6 \\
\hline
\end{tabular}

EG, experimental group; CG, control group. 
TABLe 3: Detailed intervention information 2.

\begin{tabular}{|c|c|c|c|c|c|c|}
\hline \multirow{2}{*}{ No. } & \multicolumn{3}{|c|}{ EG } & \multicolumn{3}{|c|}{ CG } \\
\hline & Intervention & Dose & Frequency & Intervention & Dose & Frequency \\
\hline 1 & Acupuncture & - & $\begin{array}{l}\text { Once a day for } 3 \text { days, then } \\
\text { performed every } 3 \text { days }\end{array}$ & Deanxit & $\begin{array}{l}\text { Flupirtine, } 0.5 \mathrm{mg} / \\
\text { meritoxin } 10 \mathrm{mg}\end{array}$ & Once a day \\
\hline \multirow[b]{2}{*}{2} & \multirow{2}{*}{ Acupuncture } & \multirow{2}{*}{-} & \multirow{2}{*}{$\begin{array}{l}\text { Once a day for, } 5 \text { times a } \\
\text { week }\end{array}$} & Deanxit & $\begin{array}{l}\text { Flupirtine, } 0.5 \mathrm{mg} / \\
\text { meritoxin } 10 \mathrm{mg}\end{array}$ & Once a day \\
\hline & & & & $\begin{array}{l}\text { Rizatriptan benzoate } \\
\text { tablets }\end{array}$ & 1 tablet & If necessary \\
\hline & Acupuncture & - & 5 times a week & & & \\
\hline 3 & Duloxetine & $\begin{array}{c}60 \mathrm{mg} / \\
\mathrm{d}\end{array}$ & Once a day & Duloxetine & $60 \mathrm{mg} / \mathrm{d}$ & Once a day \\
\hline 4 & $\begin{array}{l}\text { Acupuncture } \\
\text { TCM }\end{array}$ & - & $\begin{array}{c}\text { Once a day } \\
\text { Once dose a day }\end{array}$ & TCM & - & Once dose a day \\
\hline 5 & $\begin{array}{l}\text { Acupuncture } \\
\text { SSRI } \\
\text { antidepressants }\end{array}$ & - & $\begin{array}{l}\text { Once every } 2 \text { days } \\
\text { Once a day for } 1 \text { week, then } \\
\text { adjust the dosage. }\end{array}$ & SSRI antidepressants & - & $\begin{array}{l}\text { Once a day for } 1 \text { week, } \\
\text { then adjust the dosage }\end{array}$ \\
\hline 6 & Acupuncture & - & 5 times a week & Deanxit & $\begin{array}{l}\text { Flupirtine, } 0.5 \mathrm{mg} / \\
\text { meritoxin } 10 \mathrm{mg}\end{array}$ & $\begin{array}{c}\text { Twice a day for } 10 \text { days, } \\
\text { then once a day }\end{array}$ \\
\hline 7 & Acupuncture & - & 6 times a week & Amitriptyline & $25-150 \mathrm{mg}$ & Once a day \\
\hline
\end{tabular}

EG, experimental group; CG, control group; TCM, traditional Chinese medicine; -, not available.

TABLE 4: VAS scores in each study.

\begin{tabular}{|c|c|c|c|c|c|}
\hline \multirow{2}{*}{ Author } & \multirow{2}{*}{ Year } & \multicolumn{2}{|l|}{ EG } & \multicolumn{2}{|l|}{ CG } \\
\hline & & Before therapy mean (SD) & $4 \mathrm{w}$ mean $(\mathrm{SD})$ & Before therapy mean (SD) & $4 \mathrm{w}$ mean $(\mathrm{SD})$ \\
\hline Wang & 2012 & $7.0(1.8)$ & $2.9(1.0)$ & $6.8(1.5)$ & $3.2(1.0)$ \\
\hline $\mathrm{Ma}$ & 2015 & $7.33(1.22)$ & $4.81(1.25)$ & $7.28(1.19)$ & $5.27(1.32)$ \\
\hline Luo & 2018 & $7.92(1.16)$ & $2.29(1.01)$ & $7.86(1.22)$ & $3.12(1.25)$ \\
\hline Liu & 2013 & $3.68(1.15)$ & $0.93(0.78)$ & $3.70(1.12)$ & $2.53(1.09)$ \\
\hline Cao & 2008 & $7.50(1.12)$ & $2.34(1.43)$ & $7.48(1.27)$ & $2.40(1.45)$ \\
\hline
\end{tabular}

EG, experimental group; CG, control group.

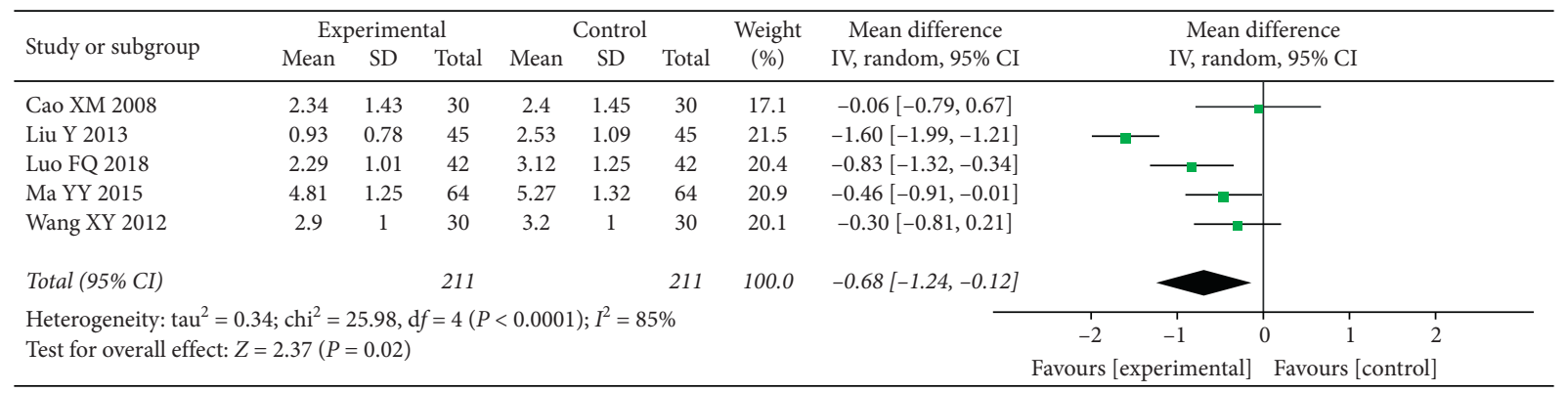

FIGURE 2: Forest plot depicting the VAS.

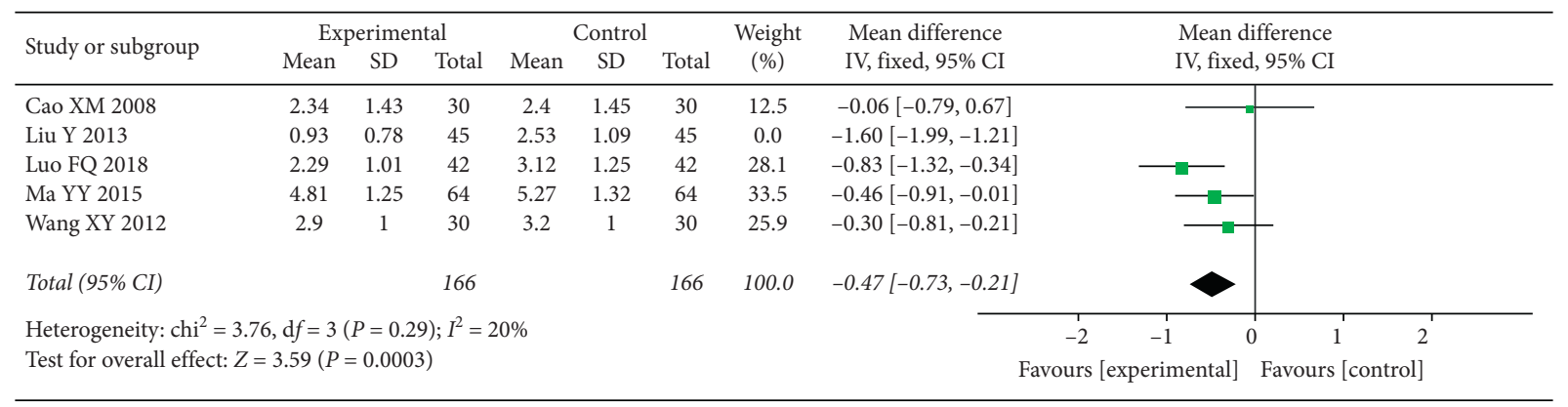

FIGURE 3: Forest plot depicting the VAS after sensitivity analysis. 
TABLE 5: HAMD scores in each study.

\begin{tabular}{|c|c|c|c|c|c|}
\hline \multirow{2}{*}{ Author } & \multirow{2}{*}{ Year } & \multicolumn{2}{|l|}{ EG } & \multicolumn{2}{|l|}{ CG } \\
\hline & & Before therapy mean (SD) & $4 \mathrm{w}$ mean $(\mathrm{SD})$ & Before therapy mean (SD) & $4 \mathrm{w}$ mean $(\mathrm{SD})$ \\
\hline Wang & 2012 & $18.5(3.8)$ & $9.3(3.9)$ & $19.4(3.4)$ & $10.9(4.9)$ \\
\hline $\mathrm{Ma}$ & 2015 & $23.88(1.86)$ & $16.20(2.40)$ & $23.91(1.56)$ & $17.60(2.29)$ \\
\hline Luo & 2018 & $11.09(2.79)$ & $4.32(1.41)$ & $11.23(2.70)$ & $7.06(2.59)$ \\
\hline Liu & 2013 & $24.08(4.96)$ & $10.84(3.86)$ & $25.13(4.96)$ & $14.33(4.12)$ \\
\hline $\mathrm{Cao}$ & 2008 & $25.87(7.76)$ & $12.07(6.92)$ & $26.43(9.00)$ & $12.90(6.01)$ \\
\hline Huang & 2000 & $26.71(5.13)$ & - & $26.87(4.25)$ & - \\
\hline
\end{tabular}

EG, experimental group; CG, control group; -, not available.

\begin{tabular}{|c|c|c|c|c|c|c|c|c|c|c|c|}
\hline \multirow{3}{*}{$\begin{array}{l}\text { Study or subgroup } \\
\text { Cao XM } 2008\end{array}$} & \multicolumn{3}{|c|}{ Experimental } & \multicolumn{3}{|c|}{ Control } & \multirow{2}{*}{$\begin{array}{l}\text { Weight } \\
(\%)\end{array}$} & \multirow{2}{*}{$\begin{array}{c}\text { Mean difference } \\
\text { IV, random, } 95 \% \mathrm{CI}\end{array}$} & \multirow{2}{*}{\multicolumn{3}{|c|}{$\begin{array}{c}\text { Mean difference } \\
\text { IV, random, } 95 \% \mathrm{CI}\end{array}$}} \\
\hline & \multirow{2}{*}{$\frac{\text { Mean }}{12.07}$} & \multirow{2}{*}{$\frac{S D}{6.92}$} & \multirow{2}{*}{$\begin{array}{c}\text { Total } \\
30\end{array}$} & \multirow{2}{*}{$\frac{\text { Mean }}{12.9}$} & \multirow{2}{*}{$\begin{array}{c}\mathrm{SD} \\
6.01\end{array}$} & \multirow{2}{*}{$\begin{array}{c}\text { Total } \\
30\end{array}$} & & & & & \\
\hline & & & & & & & 6.6 & $-0.83[-4.11,2.45]$ & & & \\
\hline Liu Y 2013 & 10.84 & 3.86 & 45 & 14.33 & 4.12 & 45 & 18.0 & $-3.49[-5.14,-1.84]$ & & & \\
\hline Luo FQ 2018 & 4.32 & 1.41 & 42 & 7.06 & 2.59 & 42 & 30.8 & $-2.74[-3.63,-1.85]$ & $\longrightarrow$ & & \\
\hline Мa YY 2015 & 16.2 & 2.4 & 64 & 17.6 & 2.29 & 64 & 32.4 & $-1.40[-2.21,-0.59]$ & - - & & \\
\hline Wang XY 2012 & 9.3 & 3.9 & 30 & 10.9 & 4.9 & 30 & 12.1 & $-1.60[-3.84,0.64]$ & & - & \\
\hline Total $(95 \%$ CI) & & & 211 & & & 211 & 100.0 & $-2.18[-3.09,-1.26]$ & & & \\
\hline Heterogeneity: tau & til & & & 0.0 & $I^{-1}=$ & & & & -4 & 0 & 4 \\
\hline Test for overall effec & $=4.66($ & $<<0.0$ & 001) & & & & & & Favours [experimental] & Favours [ & [control] \\
\hline
\end{tabular}

FIgUre 4: Forest plot depicting the HAMD.

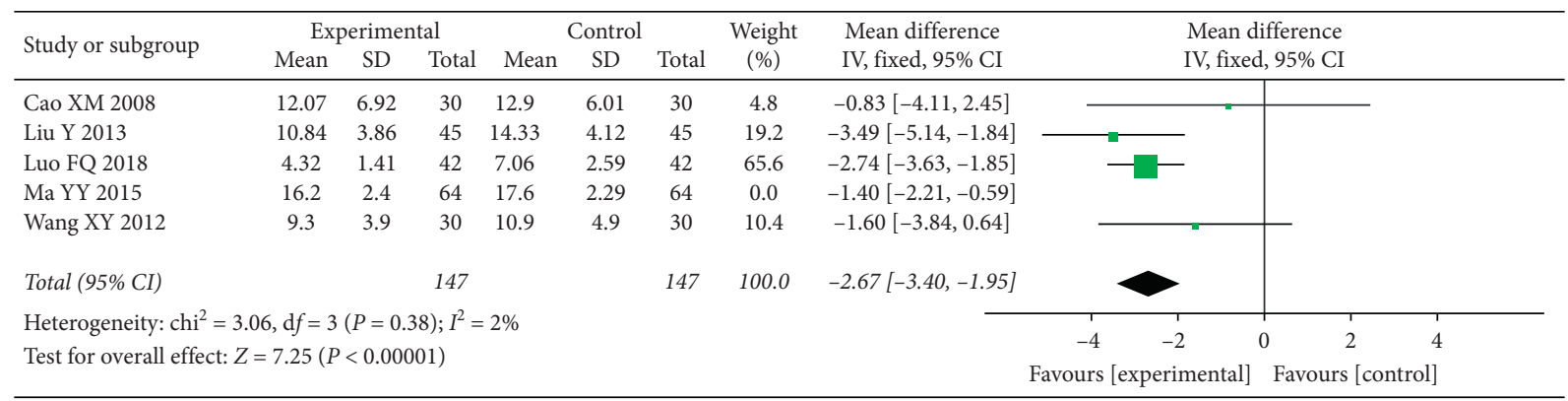

FIGURE 5: Forest plot depicting the HAMD after sensitivity analysis.

TABLE 6: Side effect scores in each study.

\begin{tabular}{|c|c|c|c|c|c|c|}
\hline \multirow{2}{*}{ No. } & \multicolumn{2}{|c|}{ Adverse events } & \multicolumn{2}{|c|}{ TESS score } & \multicolumn{2}{|c|}{ SERS score } \\
\hline & EG (\%) & CG (\%) & EG mean $(\mathrm{SD})$ & CG mean $(\mathrm{SD})$ & EG mean $(\mathrm{SD})$ & CG mean $(\mathrm{SD})$ \\
\hline 1 & $3(10 \%)$ & $15(50 \%)$ & - & - & - & - \\
\hline 2 & $0(0 \%)$ & $4(16.67 \%)$ & - & - & - & - \\
\hline 3 & $23(35.94 \%)$ & $28(43.75 \%)$ & $3.25(1.55)$ & $3.77(1.86)$ & - & - \\
\hline 4 & 7 (16.67\%) & $9(21.43 \%)$ & - & - & - & - \\
\hline 5 & - & - & - & - & $3.78(2.67)$ & $6.48(4.04)$ \\
\hline 6 & $0(0 \%)$ & $20(66.67 \%)$ & - & - & - & - \\
\hline 7 & - & - & 0 & $10.8(2.88)$ & - & - \\
\hline
\end{tabular}

EG, experimental group; CG, control group; -, not available.

The acupuncture points, frequency, and course of treatment selected in different studies were different, so there were difficulties in formulating a standardized treatment. Thus, more high-quality, rigorously designed, and well-controlled RCTs are still needed to support the clinical application of acupuncture for the treatment of chronic pain with depression.

The design of future studies in this area can play an important role in improving the quality of evidence and address the lack of evidence to support acupuncture for the 
TABLE 7: Assessment of studies' quality.

\begin{tabular}{lcccc}
\hline No. & Randomization & Blinding & Follow-up & Score \\
\hline 1 & 2 & 0 & 1 & 3 \\
2 & 1 & 0 & 1 & 2 \\
3 & 1 & 0 & 0 & 1 \\
4 & 1 & 0 & 0 & 1 \\
5 & 1 & 0 & 0 & 1 \\
6 & 1 & 0 & 0 & 1 \\
7 & 1 & 0 & 0 & 1 \\
\hline
\end{tabular}

management of chronic pain and depression comorbidity. Hence, there are some recommendations to guide future research: (i) improving methodological quality; (ii) extending follow-up periods to include intermediate- and long-term follow-up; (iii) increasing sample sizes. High-quality studies should also include costs, risks, and synergistic values of combining acupuncture with drugs compared with monotherapy otherwise.

\section{Conclusion}

Acupuncture has a promising application prospect due to its unique advantages for the treatment of chronic pain with depression comorbidity, which can be used in patients suffering from some certain chronic pain with depression comorbidity with poorer response to the conventional medication or suffering from serious side effects. Highquality RCTs are needed to support the current clinical application of acupuncture for the treatment of chronic pain with depression comorbidity and to broaden the clinical application.

\section{Data Availability}

The datasets used and analyzed during the current study are available from the corresponding author on reasonable request.

\section{Conflicts of Interest}

The authors have no conflicts of interest.

\section{Authors' Contributions}

Bin Yan, Shibai Zhu, Yu Wang, and Gula Da contributed equally to this work.

\section{References}

[1] D. A. Seminowicz and M. Moayedi, "The dorsolateral prefrontal cortex in acute and chronic pain," The Journal of Pain, vol. 18, no. 9, pp. 1027-1035, 2017.

[2] D. Feingold, S. Brill, I. Goor-Aryeh, Y. Delayahu, and S. LevRan, "The association between severity of depression and prescription opioid misuse among chronic pain patients with and without anxiety: a cross-sectional study," Journal of Affective Disorders, vol. 235, pp. 293-302, 2018.

[3] L. Martini and F. Hoffmann, "Comorbidity of chronic back pain and depression in Germany: results from the GEDA study, 2009 and 2010," Zeitschrift für Evidenz, Fortbildung und Qualität im Gesundheitswesen, vol. 137-138, 2018.

[4] B. Darlow, S. Dean, M. Perry, F. Mathieson, G. D. Baxter, and A. Dowell, "Easy to harm, hard to heal," Spine, vol. 40, no. 11, pp. 842-850, 2015.

[5] P. Lee, M. Zhang, J. P. Hong et al., "Frequency of painful physical symptoms with major depressive disorder in asia," The Journal of Clinical Psychiatry, vol. 70, no. 1, pp. 83-91, 2009.

[6] M. Beebe and R. Utley, "Primary care depression screening: relationship to chronic pain and gender," The Journal for Nurse Practitioners, vol. 14, no. 1, pp. e13-e16, 2018.

[7] WHO, Depression and Other Common Mental Disorders: Global Health Estimates, WHO, Geneva, Switzerland, 2017.

[8] WHO, The Global Burden of Disease: 2004 Update, Geneva, Switzerland, 2008.

[9] G. S. Malhi and J. J. Mann, "Depression," The Lancet, vol. 392, no. 10161, pp. 2299-2312, 2018.

[10] N. Naushad, L. B. Dunn, R. F. Muñoz, and Y. Leykin, "Depression increases subjective stigma of chronic pain," Journal of Affective Disorders, vol. 229, pp. 456-462, 2018.

[11] K. N. Alschuler, M. E. Theisen-Goodvich, A. J. Haig, and M. E. Geisser, "A comparison of the relationship between depression, perceived disability, and physical performance in persons with chronic pain," European Journal of Pain, vol. 12, no. 6, pp. 757-764, 2008.

[12] M. J. Bair, R. L. Robinson, W. Katon, and K. Kroenke, "Depression and pain comorbidity," Archives of Internal Medicine, vol. 163, no. 20, pp. 2433-2445, 2003.

[13] E. Castrén, "Is mood chemistry?" Nature Reviews Neuroscience, vol. 6, no. 3, pp. 241-246, 2005.

[14] L. Aguera-Ortiz, I. Failde, J. A. Mico, J. Cervilla, and J. J. Lopez-Ibor, "Pain as a symptom of depression: prevalence and clinical correlates in patients attending psychiatric clinics," Journal of Affective Disorders, vol. 130, no. 1-2, pp. 106-112, 2011.

[15] A. K. Schreiber, C. F. Nones, R. C. D. Reis, J. G. Chichorro, and J. M. D. Cunha, "Diabetic neuropathic pain: physiopathology and treatment," World Journal of Diabetes, vol. 6, no. 3, pp. 432-444, 2015.

[16] J. P. Blackburn, "The diagnosis and management of chronic pain," Medicine, vol. 46, 2018.

[17] J. T. Hanlon, M. Backonja, D. Weiner, and C. Argoff, "Evolving pharmacological management of persistent pain in older persons," Pain Medicine, vol. 10, no. 6, pp. 959-961, 2009.

[18] M. C. Hochberg, R. D. Altman, K. T. April et al., "American College of Rheumatology 2012 recommendations for the use of nonpharmacologic and pharmacologic therapies in osteoarthritis of the hand, hip, and knee," Arthritis Care \& Research, vol. 64, no. 4, pp. 465-474, 2012.

[19] R. Chou and L. H. Huffman, "Medications for acute and chronic low back pain: a review of the evidence for an American pain society/American college of physicians clinical practice guideline," Annals of Internal Medicine, vol. 147, no. 7, pp. 505-514, 2007.

[20] K. Y. Ho, K. A. Gwee, Y. K. Cheng, K. H. Yoon, H. T. Hee, and A. R. Omar, "Nonsteroidal anti-inflammatory drugs in chronic pain: implications of new data for clinical practice," Journal of Pain Research, vol. 11, pp. 1937-1948, 2018.

[21] C. Scarpignato, A. Lanas, C. Blandizzi, W. F. Lems, M. Hermann, and R. H. Hunt, "Safe prescribing of nonsteroidal anti-inflammatory drugs in patients with osteoarthritis--an expert consensus addressing benefits as well as 
gastrointestinal and cardiovascular risks," BMC Medicine, vol. 13, no. 1, p. 55, 2015.

[22] E. Setakis, H. G. M. Leufkens, and T. P. Van Staa, "Changes in the characteristics of patients prescribed selective cyclooxygenase 2 inhibitors after the 2004 withdrawal of rofecoxib," Arthritis \& Rheumatism, vol. 59, no. 8, pp. 1105-1111, 2008.

[23] D. Feingold, S. Brill, I. Goor-Aryeh, Y. Delayahu, and S. LevRan, "Depression and anxiety among chronic pain patients receiving prescription opioids and medical marijuana," Journal of Affective Disorders, vol. 218, pp. 1-7, 2017.

[24] J. Pierce, S. Moser, A. L. Hassett, C. M. Brummett, J. A. Christianson, and J. Goesling, "Influence of abuse history on concurrent benzodiazepine and opioid use in chronic pain patients," The Journal of Pain, vol. 20, 2019.

[25] A. Steele, "Opioid use and depression in chronic pelvic pain," Obstetrics and Gynecology Clinics of North America, vol. 41, no. 3, pp. 491-501, 2014.

[26] M. J. Bair, R. L. Robinson, G. J. Eckert, P. E. Stang, T. W. Croghan, and K. Kroenke, "Impact of pain on depression treatment response in primary care," Psychosomatic Medicine, vol. 66, no. 1, pp. 17-22, 2004.

[27] A. Ali, A. W. Arif, C. Bhan et al., "Managing chronic pain in the elderly: an overview of the recent therapeutic advancements," Cureus, vol. 10, no. 9, 2018.

[28] A. M. Sutherland, J. Nicholls, J. Bao, and H. Clarke, "Overlaps in pharmacology for the treatment of chronic pain and mental health disorders," Progress in Neuro-Psychopharmacology and Biological Psychiatry, vol. 87, pp. 290-297, 2018.

[29] R. D. Kerns, J. Sellinger, and B. R. Goodin, "Psychological treatment of chronic pain," Annual Review of Clinical Psychology, vol. 7, no. 1, pp. 411-434, 2011.

[30] J. M. Orduñavalls, C. L. Nebredaclavo, P. Lópezpais, D. Torresrodríguez, and M. Quintansrodríguez, "Characteristics of particulate and non-particulate corticosteroids. Indications for their use in chronic pain treatments," Revista Española de Anestesiología y Reanimación, vol. 63, no. 6, 2016.

[31] N. Wiles, L. Thomas, A. Abel et al., "Cognitive behavioural therapy as an adjunct to pharmacotherapy for primary care based patients with treatment resistant depression: results of the CoBalT randomised controlled trial," The Lancet, vol. 381, no. 9864, pp. 375-384, 2013.

[32] J. H. Kocsis, A. C. Leon, J. C. Markowitz et al., "Patient preference as a moderator of outcome for chronic forms of major depressive disorder treated with nefazodone, cognitive behavioral analysis system of psychotherapy, or their combination," The Journal of Clinical Psychiatry, vol. 70, no. 3, pp. 354-361, 2009.

[33] G. M. MacQueen, B. N. Frey, Z. Ismail et al., "Canadian network for mood and anxiety treatments (CANMAT) 2016 clinical guidelines for the management of adults with major depressive disorder," The Canadian Journal of Psychiatry, vol. 61, no. 9, pp. 588-603, 2016.

[34] A. Jobst, E.-L. Brakemeier, A. Buchheim et al., "European psychiatric association guidance on psychotherapy in chronic depression across europe," European Psychiatry, vol. 33, no. 1, pp. 18-36, 2016.

[35] T. Perera, M. S. George, G. Grammer, P. G. Janicak, A. Pascual-Leone, and T. S. Wirecki, "The clinical TMS society consensus review and treatment recommendations for TMS therapy for major depressive disorder," Brain Stimulation, vol. 9, no. 3, pp. 336-346, 2016.

[36] S. Goto, T. Terao, N. Hoaki et al., "Is serotonergic function associated with the antidepressant effects of modified- electroconvulsive therapy?" Journal of Affective Disorders, vol. 136, no. 3, pp. 1062-1066, 2012.

[37] J. Sheng, S. Liu, Y. Wang, R. Cui, and X. Zhang, "The link between depression and chronic pain: neural mechanisms in the brain," Neural Plasticity, vol. 2017, Article ID 9724371, 10 pages, 2017.

[38] E. Ehrich, R. Turncliff, Y. Du et al., "Evaluation of opioid modulation in major depressive disorder," Neuropsychopharmacology, vol. 40, no. 6, pp. 1448-1455, 2015.

[39] J. Salas, J. F. Scherrer, F. D. Schneider et al., "New-onset depression following stable, slow, and rapid rate of prescription opioid dose escalation," Pain, vol. 158, no. 2, pp. 306-312, 2017.

[40] K. I. Morley, J. A. Ferris, A. R. Winstock, and M. T. Lynskey, "Polysubstance use and misuse or abuse of prescription opioid analgesics," Pain, vol. 158, no. 6, pp. 1138-1144, 2017.

[41] H. Macpherson, A. Scullion, K. J. Thomas, and S. Walters, "Patient reports of adverse events associated with acupuncture treatment: a prospective national survey," Quality and Safety in Health Care, vol. 13, no. 5, pp. 349-355, 2004.

[42] T. Y. Lam, L. M. Lu, W. M. Ling, and L. Z. Lin, "A pilot randomized controlled trial of acupuncture at the Si Guan Xue for cancer pain," BMC Complementary and Alternative Medicine, vol. 17, no. 1, p. 335, 2017.

[43] L. Zhao, J. Chen, Y. Li et al., "The long-term effect of acupuncture for migraine prophylaxis," JAMA Internal Medicine, vol. 177 , no. 4 , pp. 508-515, 2017.

[44] I. Heo, M. S. Hwang, E. H. Hwang et al., "Electroacupuncture as a complement to usual care for patients with non-acute low back pain after back surgery: a pilot randomised controlled trial," BMJ Open, vol. 8, no. 5, Article ID e18464, 2018.

[45] H. MacPherson, S. Richmond, M. Bland et al., "Acupuncture and counselling for depression in primary care: a randomised controlled trial," PLoS Medicine, vol. 10, no. 9, Article ID e1001518, 2013.

[46] S. Li, Z. Li, Q. Wu et al., "A multicenter, randomized, controlled trial of electroacupuncture for perimenopause women with mild-moderate depression," BioMed Research International, vol. 2018, Article ID 5351210, 7 pages, 2018.

[47] R. Dale and B. Stacey, "Multimodal treatment of chronic pain," Medical Clinics of North America, vol. 100, no. 1, pp. 55-64, 2016.

[48] J.-H. Lee, T.-Y. Choi, M. S. Lee, H. Lee, B.-C. Shin, and H. Lee, "Acupuncture for acute low back pain," The Clinical Journal of Pain, vol. 29, no. 2, pp. 172-185, 2013.

[49] P. Bosch, M. van den Noort, H. Staudte, and S. Lim, "Schizophrenia and depression: a systematic review of the effectiveness and the working mechanisms behind acupuncture," Explore, vol. 11, no. 4, pp. 281-291, 2015.

[50] A. R. Jadad, R. A. Moore, D. Carroll et al., "Assessing the quality of reports of randomized clinical trials: is blinding necessary?" Controlled Clinical Trials, vol. 17, no. 1, pp. 1-12, 1996.

[51] X. Y. Wang and X. Y. Li, "Randomized controlled study of menopause women with depression pain treated by Bo's abdominal acupuncture," in Proceedings of the Third International Conference on Abdominal Needles, p. 7, Beijing, China, October 2012.

[52] Y. Xiao, The Curative Effect of Dialectical Find in Treatment Migraine Patients with Anxiety and Depression Clinical Observation, Hubei University of Chinese Medicine, Wuhan, China, 2015.

[53] Y. Y. Ma, D. L. Zhou, J. J. Hu, and H. Y. Wang, “The treatment of 64 cases of depression with pain by combing Duloxetine 
with acupuncture," Western Journal of Traditional Chinese Medicine, vol. 28, no. 2, pp. 108-110, 2015.

[54] F. Q. Luo, X. W. Guo, J. Zhang, S. P. Wang, and L. Ye, "Analysis of the application of acupoint acupuncture therapy on recurrent trigeminal neuralgia accompanied by anxiety and depression patients," Chinese Journal of General Practice, vol. 16, no. 8, pp. 1360-1363, 2018.

[55] Y. Liu, Y. H. Zhang, M. Jin, and W. J. Liu, "Study on clinical effect enhancement of acupuncture for depression with chronic pain treated with SSRI antidepressants," Chinese Acupuncture \& Moxibustion, vol. 33, no. 8, pp. 689-691, 2013.

[56] X. M. Cao, Z. X. Yang, H. L. Xie, Y. Zhang, J. C. Zhang, and X. D. Rao, "Randomized control study on depression induced by chronic pain treated with acupuncture," World Journal of Acupuncture-Moxibustion, vol. 17, no. 3, pp. 1-8, 2007.

[57] X. J. Huang and R. H. Luo, "Effect of acupuncture on pain of depressive neurosis," Guangdong Medical Journal, vol. 21, no. 8, pp. 704-705, 2000.

[58] L. Yang, Y. M. Di, J. L. Shergis et al., "A systematic review of acupuncture and Chinese herbal medicine for postpartum depression," Complementary Therapies in Clinical Practice, vol. 33, pp. 85-92, 2018.

[59] G. D. Baxter, C. Bleakley, and S. McDonough, "Clinical effectiveness of laser acupuncture: a systematic review," Journal of Acupuncture and Meridian Studies, vol. 1, no. 2, pp. 65-82, 2008.

[60] H. A. Anshasi and M. Ahmad, "An assessment of methodological quality of systematic reviews of acupuncture and related therapies for cancer-related pain," Complementary Therapies in Clinical Practice, vol. 32, pp. 163-168, 2018.

[61] E. Ernst and A. R. White, "Prospective studies of the safety of acupuncture: a systematic review," The American Journal of Medicine, vol. 110, no. 6, pp. 481-485, 2001. 